\title{
Un ensayo de prosopografía andina (Pongos y zoncitos)
}

\author{
Artículos originales: HISTORIA \\ Recibido: $10 / 04 / 2021$ \\ Aprobado: $25 / 06 / 2021$ \\ Publicado: $14 / 10 / 2021$
}

\author{
Wilfredo Kapsoli Escudero \\ Universidad Nacional Mayor de San Marcos \\ wckapsoli@hotmail.com
}

\begin{abstract}
RESUMEN
La Prosopografía es el estudio de los seres más excluidos de la sociedad. En este ensayo rescatamos la vida de Pongos y Zoncitos cuyas historias están olvidadas con sus sueños invisibles. Ellos con su sudor y sangre alimentaron la prosperidad de los gamonales (plantas parásitas que vivían a expensas de las cepas buenas). Los Pongos eran siervos de las haciendas ninguneados y excluidos socialmente. Los zoncitos son personajes enigmáticos que actúan como bufones para divertir a los patrones y sus allegados. Pongos y Zoncitos son también considerados como illas, es decir, deidades de la buena suerte y abundancia. Ellos testimonian su vida con metáforas y alegorías asociadas al tiempo y a la naturaleza. Tienen también sueños utópicos y que en algún momento el mundo se vuelva al revés.
\end{abstract}

Palabras Clave: pongos, zoncitos, gamonales, bufones, illas, metáforas, sueños y utopías

\section{An essay on Andean prosopography (Pongos and zoncitos)}

\begin{abstract}
Prosopography is the study of the most excluded beings in society. In this essay we rescue the life of Pongos y Zoncitos whose stories are forgotten with their invisible dreams. They with their sweat and blood fed the prosperity of the gamonales (parasitic plants that lived at the expense of good strains). The Pongos were serfs of the haciendas ignored and socially excluded. The zoncitos are enigmatic characters who act as buffoons to amuse the patrons and those close to them. Pongos and Zoncitos are also considered illas, that is, deities of good luck and abundance. They testify to their life with metaphors and allegories associated with time and nature. They also have utopian dreams and that at some point the world turns upside down.
\end{abstract}

KeYwords: pongos, zoncitos, gamonales, buffoons, illas, metaphors, dreams and utopias 


\section{Una vida en metáforas}

A uge Marc, en Las formas del olvido (1998), señala que Clifford Geertz pone en relieve las riquezas de las mediaciones simbólicas que organizan la práctica social en un mundo determinado. Es decir, «habla de la cultura como un sistema de símbolos en perpetua interacción» (p. 36). Por otra parte, Paul Ricoeur, subraya que la comprensión de las mediaciones simbólicas legitima la lectura de las prácticas sociales que se expresan a través de la historia» (p. 38).

En la década de 1980, la antropóloga Carmen Escalante recogió el testimonio de un pongo de Huancavelica, quien aceptó contar su vida. Este trabajo lo plasmó en el texto: Testimonio de un pongo, Comunidad Campesina de Pachaccla Huancavelica (1983). En su testimonio enfatizó que su relato no se puede deschatar (discutir), porque los siervos eran tratados día y noche como animales. En palabras del pongo: «Aquí en la Hacienda hemos alimentado con nuestro sudor, con nuestra sangre desde que nuestros ojos se abrieron a la luz en estas lomas. Así lo hicieron también nuestros padres y abuelos como Justo Bernaco, a quien el hacendado le nombró ullariko (transmisor de órdenes)». (p. 212).

En la época de los incas esta función lo cumplían los Tucuyricoj (los que todo lo ven) que informaban del comportamiento de los runas en los ayllus. Bartolomé de las Casas, cuando se refería a la explotación de Mitayos en los centros mineros decían: «no es el oro ni la plata los que se envían a Espańa sino la sangre y el sudor de los indios». El testimoniante de Carmen Escalante proclama: «Soy hijo de aquel atardecer de mi vida, viviendo como pongo» (lo subrayado es nuestro).

Aquí, es interesante señalar, cómo el pongo asocia su existencia con el «atardecer», esto es, envejecer en la misma situación opresiva a la que estaba sometido. $\mathrm{Al}$ inicio del testimonio dice «a mí me tocó vivir en la hacienda cuando la dueña era una vieja machona sin marido y con alma de diabla» (p. 212). Nótese que el pongo alude a la patrona en forma despectiva asociándolo con el mal y el infierno.

Nosotros tenemos que estar en su casa sin ojotas y con la 'cabeza desnuda', sin sombrero, hasta lo que ella escupía tenemos que recibirlos en una vasija de plata. Cuando ella envejecía no podía sujetarse sobre el caballo, tenemos que trasladarlo de la hacienda Pachaclla hasta Huancavelica en 'andas entre cuatro pongos'.

Para ver el trabajo de los pongos en las chacras y campos de cultivo, tenemos que cargar a la patrona en andas y cada domingo lo bajábamos al templo de Santa Ana. Después de la misa lo volvíamos a cargar hasta la Casa Hacienda. (p. 212)

Y continúa el relato:

Cuando uno entra el pongo la hacienda nunca nos daba de comer, cada pongo tenía que entrar cargado de sus víveres y si los víveres se terminaban pasábamos hambre. Esta patrona era una mujer sin alma, a pesar de que en su casa había cuartos llenos de chuño (papa deshidratada). ¿de dónde era esa papa? Era lo que nosotros trabajábamos. Nuestra patrona María Lozano quedó viuda muy joven. Ella era una cristiana sin alma, verdadero nido del diablo. Cuando se perdía el ganado en la Hacienda, teníamos que reponerlo nosotros con la cantidad que quería. Asi, ;Cuánto nos hizo llorar!, hasta que las lágrimas se sequen en nuestros ojos (lo subrayado es nuestro). Esta patrona envejeció en nuestras manos y su vejez ha sido un verdadero castigo porque ha padecido peor que un animal. No se daba cuenta de lo que se había cagado en la cama. Ya no hablaba, sin lengua se arruinó. Murió terminado por el piojo. Se quedó muda, no hablaba, solo mugía. Durante el día, dos pongos no nos movíamos de su lado, no se sujetaba ni parada ni sentaba, nosotros lo bajábamos y los sentábamos. Cuando nos sentábamos se iba como un trompo. Comía hasta la saciedad, todo se engullía como un pato, luego decía ibasta! A pesar de nuestros cuidados los piojos lo terminaban, aparecian como hormigas. La ropa lo haciamos hervir en peroles, pero, aun asi, los piojos lo terminaban. (p. 217)

Carmen Escalante apunta que, al ver estas escenas, los comuneros decían Chiki (envidia), el anuncio de un mal agüero, era la premonición para que desaparezca todo el ganado y aún su vida. Concluyendo esta parte del relato, el testimoniante dice «este fin animal ha tenido nuestra patrona, su vida en nuestras manos se acabó». Murió callada sin decir palabra alguna «su 
suerte ha sido padecer y castigo porque esta patrona hasta el último, solo odio, tristeza y nos hizo llorar a toda su gente». (p. 218)

Continúa Carmen Escalante explicando que cuando el pongo realizaba tarea de pastoreo y se le perdía una cría o una madre de oveja o se lo comía el zorro si era "merino" (ganado fino) se reponía con ovejas chuscas el rebaño del pastor. No había dónde quejarse, "la hacienda mandaba como quería y nunca estaba contento». Ellos justificaban esta acción diciendo que los indios se apropiaban del ganado por vicio.

En estas lomas hay mucho zorro, para eso la hacienda enviaba veneno en carne, para colgarlo en el cuello de las crías enfermas; así se las dejaba lejos de las estancias, entonces cuando estas crías se dejaban, lloraban de noche y los zorros acudían de todas partes, ahora algunos zorros, regresándose morían en el camino, otros dentro de sus huecos. Porque si mandaba veneno para 6 u 8 zorros, había que buscar los zorros muertos hasta encontrar para llevarlos a la hacienda; porque si faltaba decía, seguro que no has puesto completo y te has comido la cría, diciendo así: se reponía con un borrego de nuestra tropa. (p. 219)

Lo que describe el pongo nos hace ver un fenómeno de dominación total que no era cuestionado por nadie. «La lana se sacaba a Ica. Este viaje duraba semanas o meses y el fiambre que nos llevábamos era de nuestra despensa» (p. 220). A lo que agrega: «la hacienda sólo nos entregaba lana pesada ya y era de nuestra responsabilidad llegar como sea con la lana a Ica, en un plazo fijado por el patrón» (p. 221). En fin, "Ir a Ica era apostar con la muerte. Muchos ya no regresaban. Morían en el camino o regresaban enfermos a morir con chukchu (paludismo, terciana). Mi padre transportaba en mulas la fibra de alpaca y el chuño a Ica, regresó con chukchu y curándole día y noche, le hicieron regresar ya de la mitad del camino a la otra vida». (p. 221).

Con este mal del paludismo a uno le da alta calentura y ataques de temblor de pies a cabeza. Esta enfermedad entra en el momento que uno se asusta y también se expulsa el mal con otro susto. Así el tayta Clemente, cuando regresó de Ica empezó a dormir día y noche y cuando despertaba le daba la tembladera que lo obligaba a correr sin control. Un día tropezó con un toro bravo que lo embistió y le sacudió un fuerte espanto y el chukchu escapó de susto de su cuerpo ${ }^{1}$. (p. 221)

A pesar de los estragos que causaba la peste, los campesinos se burlaban de la enfermedad a través de bailes alusivos al tema. Y explica Carmen Escalante:

Los pongos, para bajar a la costa, semanas antes se curaban con medicamentos de los más hediondos, hasta que estén totalmente penetrados de olores pestilentes. Tomaban orines fermentados, kerosene, se untaba con excremento humano fermentado, con orín de zorrino, se sahumaba con humo de jebe de cuerno derecho de los toros negros y de los chivos capones, con humo de maderos de cruces abandonadas del campo santo. Cuando eran penetrados del todo por estos olores, el chukchu no se les acercaba, estos olores lo ahuyentaban. Y para abrirse paso del chukchu, en el camino a la costa, llevaban puesto un collar hecho de uñas de zorrinos, de chivos y de picos de chiwako. (p. 222).

Estos ritos en pos de la salud eran costumbres consuetudinarias y estaban legitimados socialmente.

El pongo precisa: «Ellos nos gritaban ¡apura burro!, japura talegón! ¡apura gran puta CARAJO! Solo esas palabras recibíamos. Cuando nos expulsaron de la hacienda, salíamos sin nada. Éramos llevados solo por nuestra cabeza. Asi aparecíamos regados por todas partes con lágrimas de lluvia, con lágrimas de río; como errantes si pueblo, sin familia. Asi andamos en el tiempo de la hacienda, que de padre solo tuvimos al viento y de madre a la neblina de estas lomas. Nos arrastrábamos de loma en loma. Asi éramos como si no hubiéramos sido paridos por esta tierra» (p. 225). (lo subrayado es nuestro).

1 Sal y Rosas, Federico. Psicólogo ancashino, dice que el mal del susto da lugar a la «separación del alma del cuerpo por la acción de la tierra. Tal sustracción del espíritu (jani) se debería al enojo de la tierra ante el susto del hombre, por lo cual el regreso o rescate de aquel requería sustancialmente la invocación y ofrendas a las divinidades». Observaciones en el Folklore Psiquiátrico. En: Folklore Americano, Lima, año $20 \mathrm{~N}^{\circ} 17$, 1971, pág. 249 al 262. También puede curarse con el Jacacupe o sobe con el cuy para sacar el manchainisca (susto). Se puede realizar igualmente el shocma (ficción del cuerpo con flores y hojas de coca). 
En la cosmovisión andina el agua de las lluvias, los ríos y las lagunas eran considerados esenciales para la producción y la existencia individual y colectiva.

Por último, alguien dice sin pensar como si no tuviéramos cabeza " $i$ No puede ser! Que no recuerden cómo arrastramos el sufrimiento en tiempo de la hacienda, porque hasta el chancho tiene memoria. Por eso, esa vez, al escucharlos mi corazón ardía y de rabia me retorcía. Si hubiera tenido fuete, a los dos los hubiera fueteado. Porque jen la cabeza de quién cabe, que el tiempo de la hacienda pueda regresar? $\mathrm{Y}_{¿}$ Cómo ya lo que está cocido puede volver a ser crudo?». (p. 225).

Esta es una metáfora de elogio a la comida, es decir al alimento ya preparado. Los pongos, a pesar de todo, tenían momentos de alegría, como las kachwas (bailes) durante la trilla del trigos, alverjas y cebadas, donde

... la gente bailando pisaba los granos, se hacía de noche entre peones solteros. Los varones pisaban, las muchachas iban a dar aliento, él iba con bombo y quena cantando y tocando. El dueño da a todos coca, trago y cigarro, los jóvenes se agarran de las manos y corren a toda fuerza, a trote, se forman dos bandos y frente a frente corren. Da la vuelta a la era y vuelven a empezar de nuevo, las chicas mujercitas, pasñas van a cantar a fin de enamorar a los jóvenes solteros y tener relaciones. (p. 227)

Eran tiempos de la iniciación sexual y de socialización. También en aquella época practicaban el culto a las Apachetas (montículo de piedra). En todas las cumbres siempre habían piedras grandes y redondas, lustrosas como si hubiera sacado brillo. Con ellas prueban sus fuerzas los jóvenes. Acto que era conocido como el pulso rumi y otros conocidos como el azul wari, consideraba piedras secretas que lo guardaba en su corazón. En estos ritos decían oraciones secretamente. Cuando ningún hombre lo levantaba por ser muy pesada, lo trasladaban en mantas cargándolo entre varios, por eso los hacendados se consideraban apachetas o piedras sagradas.

\section{Bufones e illas}

El antropólogo Washington Rozas, al inicio de su ensayo "El zoncito y la hacienda una interpretación de su ambigüedad» (2013), nos relata cómo nació su interés por el tema. Recuerda que en sus notas de campo «había escrito varias páginas sobre la vida y funciones que tenía el zoncito en la hacienda serrana» (p. 1). Henry Favre, citado por Rozas, considera hacienda «a toda propiedad individual de tierras, cualquiera sea su extensión, sobre la que vive una población estable, directa e individualmente ligada al propietario o a su representante por una serie de obligaciones personales, tanto materiales como simbólicas, que la mantienen en estado de servidumbre, admitida o disimulada, o por lo menos en una situación primitiva de dominio y dependencia» (p. 3).

Era costumbre de los hacendados tener zoncitos que jugaban un papel importante porque simbólicamente la presencia de ellos les traía «buena suerte». Por eso los trataban como un fetiche festivamente. Ellos tenían una serie de obligaciones, tanto como mitanish o peones.

Los pongos eran sirvientes que tenían una serie de obligaciones personales tanto como mitanish como peones. El zoncito realizaba tareas domésticas como trasladar agua y leña a la cocina, preparaba alimentos de los animales como son los perros, cerdos, cuyes y gallinas. En ocasiones, también cuidaban a las vacas lecheras y ayudaban a ordeñarlos. No recibían salario ni usufructuaba las tierras del patrón. Su trabajo se reconocía con comida, la ropa y la vivienda que le facilitaban. Su presencia era extravagante, harapiento, es decir, tenía un estereotipo original. Vivía solo el presente, sin recuerdo del pasado y tampoco inquietudes por el futuro. (p. 6).

Estos servicios eran conocidos también como:

El pongeaje y mitani que eran trabajos obligados que recibían a entrar al servicio de la hacienda durante una semana sin remuneración monetaria, pero a cambio recibía comida y productos agrícolas. La otra obligación era cumplir labores agrícolas: siembra, barbecho, aporque y cosecha. Todo ello a cambio de comida y coca. Como se puede 
notar, muchas costumbres y creencias de la época de la hacienda fueron practicadas hasta antes de la Reforma Agraria (pp. 3-4).

\subsection{Bufones}

Los nobles españoles tenían por costumbre poseer bufones (persona que hace tonterías o se comportan con poca seriedad pretendiendo ser cómicos y resultando ridículos). En el palacio de los reyes existía una curiosa banda de bufones (enanos o discapacitados psíquicos) que formaban parte de la vida cotidiana en la Corte. Su función consistía en divertir a los monarcas y grandes señores. En la pintura de Diego Velásquez, en el motivo de las Meninas aparece un enano que da una patada al perro. Washington Rozas se pregunta ¿Quién era el bufón? contesta: «un personaje, un pícaro, gracioso, humorista, que, con sus palabras, acciones y chistes hacía reír a los nobles. Son aquellas personas que hacen y dicen tonterías frente a los demás».

En las haciendas los bufones hacían lo grotesco para divertir a los visitantes esporádicos o cotidianos y también actuaban durante las jornadas agropecuarias para que el trabajo no fuera aburrido ni pesado. A los zoncitos les ponían apodos con los que la gente los ridiculizaba. Les decía, por ejemplo, compadre, sargento thantaña (haraposo) o simplemente opa (zonzo). No tenía documentación alguna, solo referencias del bautizo en las haciendas, por tanto, eran personajes sin existencia real para la nación peruana. (p. 8).

No podían contraer matrimonio ni tener familia. Estaban condenados a ser wakchas (pobres) y como tal eran mal vistos socialmente. A los zoncitos les sometían a vejámenes en las moliendas de la caña de azúcar o la fabricación de la chancaca. Así, una noche de molienda, el zoncito se durmió y uno de los peones le untó los ojos con melaza de cańa. Al despertar, el zoncito no pudo abrir los ojos y se desesperaba, provocando la risa de los presentes, pero, él se vengaba de los intrusos y cuando los molineros se dormían les orinaba, sacudiéndose en el altillo (p. 10). El zoncito no tenía noción del más allá y la patrona le preguntaba: ¿Cuando te mueras, a dónde deseas ir? ¿al cielo? No, le contestaba, ¿al purgatorio? Tampoco, ¿al infierno? ¡Ni pensar! Cuando yo me muera me iré a Andahuaylas, ocurrencia que festejaba el hacendado riéndose.

En síntesis, según Washington Rosas:

Los zoncitos jugaban una función importante en la hacienda: la de entretener y divertir al hacendado y a su familia. A pesar de que recibía vejaciones, burlas, chacotas de parte de los peones. El zoncito no se daba cuenta de su gracia y payasada. Los papelones que hacían para risa de los demás, eran involuntarios. No se preocupaba de su alimentación, ropa ni tampoco pedir algún antojo cuando los comerciantes (wasaqepes) aparecían en la hacienda. Los zoncitos oscilaban entre el entretenimiento y la ingenuidad. Se movían dentro de una delgada línea entre la normalidad y la anormalidad. Tenían la potestad de expresar cosas que los peones no se atrevían a decir frente al hacendado. Por ejemplo, según lo mencionó uno de los informantes, cierta vez un zoncito advirtió al hacendado que, en su viaje se portara bien porque era gritón y boca suelta. (p. 11).

Muchos zoncitos poseían talento para la música y la fiesta del patrono San Isidro El Labrador donde tocaban bombos o tambores. En suma, en torno a ellos existían muchas tradiciones, entre otras que traían la buena suerte, por eso eran considerados amuletos sagrados.

\subsection{Illas}

Según José María Arguedas (1966), Illa era aquella persona o representación de algún animal o cosa que reportaba la buena suerte. Parecían estrellas o piedras deformes a manera de ídolos y tenían vida, si un hombre los encontraba tendría fortuna y, sobre todo, poder, eran conocidos también como Qonopas, pequeñas esculturas de piedra que tienen forma de llamas, alpacas, cuyes, maíz y papa. Eran objetos ceremoniales, las personas que lo conseguían veían crecer su ganado y sus cosechas agrícolas. Solo la caída de un rayo podía afectarlos. Eran estampas sagradas (p. 266).

Por su parte, Diego Gonzáles Holguín, en su diccionario sobre la Lengua Quechua, traduce la palabra Iclla de la siguiente manera: "piedras o vetas grandes 
como un huevo que la persona lleva para ser rico y venturoso». (1989, p. 336).

El patrón de la hacienda creía que los zoncitos hombres o mujeres «traían más suerte». Pensaban que los zoncitos espantaban a las almas en pena, a las calamidades y pestes. También ayudaban a encontrar los Tapados (tesoro escondido) como lo ha señalado para el Valle Mantaro Takahiro Kato. Creían que los Illas recibían revelaciones en sueños sobre la existencia de tesoros ocultos por lo cual se asociaban con los huaqueros. Decían que en las noches lóbregas arden con luz radiante de color amarillo anunciando la presencia del oro y la plata de los Incas.

Los zoncitos se pensaban que también eran protegidos por los Apus, por lo mismo recibían parapus u ofrendas con fetos de llama, chicha y hoja de coca. Washington Rosas, comenta también: «En una hacienda contaban que el zoncito tenía la costumbre de madrugar muy temprano, al tercer canto del gallo ya estaba levantado y hacia bulla que no dejaba dormir al mayordomo. Un día pensó el mayordomo hacerle una broma para que se asuste. Antes que el zoncito se levantara, el mayordomo le esperó en la acequia donde acostumbraba lavarse; estaba cubierto con una manta blanca haciéndose fantasma. El zoncito al verlo, se encolerizó y le agredió a pedradas». (Rozas, p. 12)

En suma, una hacienda sin un zoncito no tenía atractivo alguno.

\section{Sueños y utopías}

En el mundo andino existe la creencia de que los sueños pueden transmitir revelaciones acerca de la existencia de los tesoros escondidos de los incas. Los testimoniantes dicen que cuando los ancianos sueñan con un ídolo, con excremento humano o con un niño, son indicadores que el huaquero encontrará la riqueza con los Tapados. "Los Tapados arden durante la noche y el color con que arde es indicador del metal. Si es amarillo significa oro y si es blanco, con seguridad es plata». Se cree que los Tapados al ser hallados se cobran la vida de una persona porque ellos son Apus que viven en los cerros o en la Pachamama (Madre Tierra). Los Tapados, almacenan un haz ve- nenoso conocido como el antimonio, que mata a las personas cuando éstos los aspiran, los zoncitos juegan un papel importante en el hallazgo del tesoro. Un testigo contó a Washington Rozas el hallazgo de un tesoro en Calca (Cusco):

Se necesita una técnica especial para desenterrar un tesoro. Lo primero que se debe hacer es pagar al Apu y a la Pachamama con un buen despacho en agradecimiento de su tapado. Luego, se debe buscar a un opa para que excave, él se encargará de desenterrar el tesoro. El opa no debe ser del lugar. El Apu y la Pachamama piden como pago a un ser humano. Algunos huaqueros pagan con un feto humano, pero la Tierra no siempre está contenta y puede llevarse al huaquero. Para evitar eso, sacrifican al zoncito. Una forma de sacrificarlo, es haciendo que excave, y la Tierra es a él a quién se lo llevará. Otros dicen, que después que excava lo ahorcan y entierran en el mismo lugar del Tapado. (p. 14).

José María Arguedas tradujo al castellano un famoso cuento llamado El Sueño del Pongo o Oponsoc Moscoinin que adquiere mayor realce al ser escrito en quechua como parte de la literatura oral. Este relato nos remite la historia de Miguel Ugayapa donde «el pongo es ingenioso y diestro para el desarrollo de muchos malabares». El pongo también es el servidor del auki y de los huamanis, sirve también como curandero porque él es un iniciado en ese oficio y está en condiciones en comunicarse con el espíritu de las montañas. El pongo no es un Laica (brujo) sino más bien se relaciona con los dioses para destruir a quienes le ofenden.

El autor de Los ríos profundos dedicó el cuento a la memoria de don Santos Ccoyoccoci de la comunidad de Canmutu de la provincia de Quispicanchi Cusco, quien vino a Lima en varias ocasiones y regresó a su pueblo cargando a espalda materiales escolares y donaciones que recibió «su majestuosa y tierna figura seguirá protegiendo desde la otra vida a su comunidad y acompañando a quienes tuvimos la suerte de ganar su afecto y recibir el ejemplo de su tenacidad y sabiduría». (Arguedas, 1969, p. 55).

Arguedas escuchó el cuento en Lima, contado por un comunero de Qasha de la Provincia de 
Quispicanchis. No pudo grabar su versión, pero ella quedó "casi copiada en mi memoria» dice José María. Oscar Núnez Prado contó otra versión muy diferente del mismo tema. Nuestra versión es lo más fiel posible al original, aunque «hay mucho de nuestra propia cosecha»-testimonió Arguedas-. Las palabras en castellano diluidos en la poderosa corriente de la lengua quechua se confunden con la sabiduría e inspiración admirable de los testimoniantes, como son soncco llaqui (tristeza del corazón), cielo ñawjiwa (ojo que colma del cielo). De este modo, "al lector que no habla quechua le llevará directo al estilo de nuestra lengua indígena tradicional que se mantiene con todos sus matices y características del ser vivo que se defiende triunfalmente. (p. 54).

José María describe al pongo: «Era pequeño, de cuerpo miserable, de ánimo débil, todo lamentable; sus ropas, viejas» (p. 57). El gran señor de la hacienda, no podía contener la risa cuando el hombrecito le saludaba. ¿Eres hombre u otra cosa? Preguntó delante de todos los sirvientes de la hacienda. Humillándose, el pongo no contestaba nada «atemorizado, con los ojos helados, se quedó de pie». Por lo menos sabrás lavar ollas. "Llévense a esta inmundicia» ordenó a uno de sus mayordomos. Arrodillándose, el pongo le besó la mano al patrón y todo agachadito siguió caminando hasta la cocina. El hombrecito tenía cuerpo pequeño, pero sus fuerzas eran como de cualquier hombre común. Cumplía con todos los trabajos. Pero había en él un espanto en su rostro y algunos se reían viéndolo así y otros lo compadecían. Expone en el relato:

Huérfano de huérfanos; hijo del viento de la luna debe ser el frío de sus ojos, el corazón pura tristeza», había dicho la mestiza cocinera, viéndolo. En otras ocasiones, al final de la tarde, cuando los siervos se reúnan para rezar el Ave María «el patrón lo martirizaba delante de toda la servidumbre, lo sacudía como a un trozo de pellejo». También lo obligaba a arrodillarse «creo que eres perro» ¡ladra! Les decía, pero el hombrecito no podía ladrar ¡Ponte en cuatro patas! Le ordenaba, a lo cual el pongo le obedecía y daba unos pasos en cuatro pies. ¡Trota como perro! Seguía ordenándole. El hombrecito salía a correr como imitarlo a los pequeños perros de las punas. Entonces, el patrón reía de buena gana y la risa le sacudía en todo el cuerpo. ¡Regresa! Le gritaba cuando alcanzaba el extremo del gran corredor. El pongo volvía y llegaba fatigado, mientras tanto los sirvientes rezaban el Ave María despacio como viento interior en el corazón. (p. 59)

Y continúa;

Ahora ¡alza las orejas como vizcacha! ¡Vizcacha eres! ¡siéntate en dos patas! «como si en el vientre de su madre hubiera sufrido la influencia modelante de alguna vizcacha, el pongo imitaba exactamente la figura de uno de estos animalitos». Recemos el Padre Nuestro, decía el patrón a los indios que esperaban en fila. El pongo no podía rezar porque no estaba en el lugar que le correspondía. Los siervos se dispersaban ¡Vete, pancita! Decía el patrón. Todos los días le obligaba a revolcarse, lo obligaba a reírse, a fingir llanto. Lo entregó a la mofa de sus iguales, los colonos. Es decir, sus indios de la hacienda.

Una tarde a la hora del Ave María, cuando están reunidos todos los colonos, el hombrecito habló muy claramente, aunque su rostro seguía muy espantado:

«-Habla... si puedes — contestó el hacendado.

—Padre mío, señor mío, corazón mío —empezó a hablar el hombrecito- Soné anoche que habíamos muerto los dos juntos; juntos habíamos muerto.

— ¿Conmigo? ¿Tú? Cuenta todo, indio - le dijo el gran patrón.

- Como éramos hombres muertos, señor mío, aparecimos desnudos, los dos juntos; desnudos ante nuestro gran Padre San Francisco.

— ¿Y después? ¡Habla! —ordenó el patrón, entre enojado e inquieto por la curiosidad.

-Viéndonos muertos, desnudos, juntos, nuestro gran Padre San Francisco nos examinó con sus ojos que alcanzan y miden no sabemos hasta qué distancia. A ti y a mí nos examinaba, pesando, creo, el corazón de cada uno y lo que éramos y lo que somos. Como hombre rico y grande, tú enfrentabas esos ojos, padre mío.

- ¿Y tú?

—No puedo saber cómo estuve, gran señor. Yo no puedo saber lo que valgo. 
Luego siguió: "Nuestro padre dijo con su boca: «De todos los ángeles, el más hermoso, que venga. A ese incomparable que lo acompañe otro ángel pequeño, que sea también el más hermoso. Que el ángel pequeño traiga una copa de oro, y la copa de oro llena de miel de chancaca más transparente». Esta orden aparentemente iba direccionado a favor del patrón.

Pero, dueño mío: apenas nuestro gran Padre San Francisco dio la orden, apareció un ángel, brillando, alto como el sol; vino hasta llegar delante de nuestro Padre, caminando despacio.

Luego San Francisco ordenó "Ángel mayor: cubre a este caballero con la miel que está en la copa de oro; que tus manos sean como plumas cuando pasen sobre el cuerpo del hombre, diciendo, ordenó nuestro gran Padre. Y así el ángel excelso, levantando la miel con sus manos, enlució tu cuerpecito, todo, desde la cabeza hasta las uñas de los pies. Y te erguiste, solo; en el resplandor del cielo la luz de tu cuerpo sobresalía, como si estuviera hecho de oro, transparente». (p. 62)

Este pasaje reflejaba aparentemente una satisfacción de clase. Así:

-Cuando tú brillabas en el cielo, nuestro gran Padre San Francisco volvió a ordenar: "Que de todos los ángeles del cielo venga el de menos valer, el más ordinario. Que ese ángel traiga en un tarro de gasolina excremento humano». Así, «Un ángel que ya no valía, viejo, de patas escamosas, al que no le alcanzaban las fuerzas para mantener las alas en su sitio, llegó ante nuestro gran Padre; llegó bien cansado, con las alas chorreadas, trayendo en las manos un tarro grande». Finalmente, nuestro gran Padre ordenó: «Embadurna el cuerpo de este hombrecito con el excremento que hay en esa lata que has traído; todo el cuerpo, de cualquier manera; cúbrelo como puedas. ¡Rápido!, entonces, aparecí avergonzado, en la luz del cielo, apestando...». Es en estas circunstancias cuando nos vimos juntos, los dos, ante nuestro gran Padre San Francisco, él volvió a mirarnos, a ti ya a mí, largo rato. Con sus ojos que colmaban el cielo, no sé hasta qué honduras nos alcanzó, juntando la noche con el día, el olvido con la memoria. Y luego dijo: "Todo cuanto los ángeles debian hacer con ustedes ya está hecho.
Ahora jlámanse el uno al otro! Despacio, por mucho tiempo». El viejo ángel rejuveneció a esa misma hora; sus alas recuperaron su color negro, su gran fuerza. Nuestro Padre le encomendó vigilar que su voluntad se cumpliera». (pp. 62-63)

San Francisco de Asís es considerado como el santo de los pobres. Miguel de Unamuno dice que «San Francisco fue el más auténtico cristiano, sin duda, el cristiano perfecto, humanamente imposible, cristiano yo diría que trágico y armónico. Y que mal se me entiende estos conceptos que son sentimientos. Ser perfectos como nuestro padre celestial que está en los cielos. El Cristo nos puso como una meta lo inaccesible y San Francisco con la estricta observancia, con la observancia agónica y trágica que no excluye la alegría» (Robles, 2000). A su vez trascribe una leyenda llena de símbolos mágico religiosos. Se trata del Pozo de Santa Clara que es presentado poéticamente:
La cara fresca de Santa Clara vio Francisco en el lecho de un pozo y del agua bebió con su mano y al gustar el claror de la cara se bañó las entrañas de gozo aclamando su senda el Hermano.

Al claro frescor de la Luna claridad, caridad, la pobreza toda su fortuna claror de la hermandad.

¿Por qué la tradición cristiana en el mundo andino evocaba la santidad de San Francisco de Asís? Seguramente por la recuperación de la dignidad humana y por el valor simbólico de la pobreza terrenal que será recompensada en el más allá, en el Reino de los Cielos.

Juan Pérez de la Riva, historiador cubano, escribió hace unas décadas el libro titulado: Para una Historia de las Gentes sin Historia. Allí el autor se propone sacar a la luz a unos protagonistas de la historia que apenas son mencionados. Se trata de aquellos hombres olvidados que requieren ser rescatados y conocer su vida cotidiana para comprender mejor las raíces de la explotación humana y las particularidades del presente. Aunque Marc Augé (1998) considera que: 
... hay que saber olvidar para saborear el gusto del presente, del instante y de la espera. La propia memoria necesita también del olvido, hay que olvidar el pasado reciente para recobrar el pasado remoto». De este modo, será posible una lectura dialéctica de la realidad histórica social, donde incluso «las peripecias del sueño prolongan la de la vigilia, cambiando así vigilia y sueño como una continuidad, de tal suerte que ambas concepciones formaban parte un solo relato. (p. 9)

Nuestro ensayo sobre Pongos y Zoncitos se ha inspirado en las propuestas de Juan Pérez de la Riva, Laurence Stone, Marc Augé y José María Arguedas. Esperemos que los lectores se suman a otras tareas similares que enriquezcan nuestro oficio y recuperen la memoria de los hombres anónimos e invisibles en nuestro país.

\section{Conclusiones}

1. Los Pongos y Zoncitos son los personajes más excluidos de la sociedad andina y se desempeñaban como siervos en las haciendas serranas.

2. Estos personajes eran maltratados, deshumanizados y tratados como animales sin que ellos pudieran quejarse ante ninguna autoridad buscando justicia social.

3. Los Pongos y Zoncitos formaban parte del paisaje latifundista al ser considerados también como Illas y Bufones por lo mismo proveedores de la abundancia y la diversión de sus amos.

4. Los Pongos y Zoncitos asociaban su existencia a través de metáforas relacionadas con la naturaleza y la cosmovisión andina.

5. Los Pongos y Zoncitos en ocasiones, tenían ciertos momentos de alegría y alimentaban sueños utópicos de condena a sus amos. En una palabra, esperaban la llegada de un Pachacuti (un mundo al revés).

\section{Bibliografía}

Arguedas, José María (1966). Mitos, cuentos y leyendas. Lima: Instituto de Cultura.

Arguedas, José María (1969). El sueño del pongo. Santiago de Chile: Editorial Universitaria.

Auge, Marc (1998). La forma del olvido. Barcelona: Editorial Gedisa.

Escalante, Carmen (1983). "Testimonio de un pongo, Comunidad Campesina de Pachaccla, Huancavelica». En: Testimonio: Hacia la sistematización de la historia oral. Lima: Ed. Fundación Friedrich Ebert, CIESUL, $1^{\circ}$ edición, pp. 211-226.

Gonzales Holguín, Diego (1989). Vocabulario de la Lengua General de Todo el Perú llamado Lengua Quichua o del Inca. Lima: Editorial. UNMSM.

Kapsoli, Wilfredo (1987). Movimientos campesinos en el Perú. Lima: Editorial Atusparia.

Kapsoli, Wilfredo (1989). Historia y psicología del indio. Lima: Ed. Caribe.

Kato, Takahiro (1991). «Los Tapados en el valle del Mantaro». En Revista Antropológica 9. Lima: Pontificia Universidad Católica del Perú.

Robles, Laureano (2000). "Texto inédito de Unamuno sobre San Francisco». Separata de Naturaleza y Gracia. Salamanca Vol. XXXXVII.

Rozas, Washington (2013). El zoncito y la hacienda una interpretación de su ambigüedad. Disponible en: https:// docplayer.es/9381444-El-zoncito-y-la-hacienda-unainterpretacion-de-su-ambiguedad-jesus-washingtonrozas-alvarez.html

Sal y Rozas, Federico (1971). "Observaciones en el Folklore Psiquiátrico». En Folklore Americano. Año 20, $\mathrm{N}^{\circ} 17$, Lima. 